\title{
Foliar water uptake: a common water acquisition strategy for plants of the redwood forest
}

\author{
Emily Burns Limm · Kevin A. Simonin • \\ Aron G. Bothman · Todd E. Dawson
}

Received: 19 February 2009/Accepted: 5 June 2009/Published online: 8 July 2009

(c) The Author(s) 2009. This article is published with open access at Springerlink.com

\begin{abstract}
Evaluations of plant water use in ecosystems around the world reveal a shared capacity by many different species to absorb rain, dew, or fog water directly into their leaves or plant crowns. This mode of water uptake provides an important water subsidy that relieves foliar water stress. Our study provides the first comparative evaluation of foliar uptake capacity among the dominant plant taxa from the coast redwood ecosystem of California where crown-wetting events by summertime fog frequently occur during an otherwise drought-prone season. Previous research demonstrated that the dominant overstory tree species, Sequoia sempervirens, takes up fog water by both its roots (via drip from the crown to the soil) and directly through its leaf surfaces. The present study adds to these early findings and shows that $80 \%$ of the dominant species from the redwood forest exhibit this foliar uptake water acquisition strategy. The plants studied include canopy trees, understory ferns, and shrubs. Our results also show that foliar uptake provides direct hydration to leaves, increasing leaf water content by $2-11 \%$. In addition, $60 \%$ of redwood forest species investigated demonstrate nocturnal stomatal conductance to water vapor. Such findings indicate that even species unable to absorb water directly into their foliage may still receive indirect benefits from nocturnal leaf wetting through suppressed transpiration.
\end{abstract}

Communicated by Frederick C. Meinzer.

E. B. Limm $(\bowtie)$ · K. A. Simonin · A. G. Bothman .

T. E. Dawson

Department of Integrative Biology, University of California,

Berkeley, CA 94720, USA

e-mail: emlimm@berkeley.edu
For these species, leaf-wetting events enhance the efficacy of nighttime re-equilibration with available soil water and therefore also increase pre-dawn leaf water potentials.

Keywords Leaf wetness - Water absorption .

Nocturnal conductance $\cdot$ Stable isotopes $\cdot$ Deuterium

\section{Introduction}

Most biologists consider precipitation occurring as rain or snow in temperate climates to be the only significant sources of water contributing to terrestrial ecosystem water balance and therefore productivity (Mather and Yoshioka 1968; Stephenson 1990). However, investigation of this assumption reveals that wetting of leaves and plant crowns with fog, cloud-borne mist, and dew may often provide a significant water subsidy in many ecosystems and thereby positively affect plant water balance without noticeably increasing soil wetness (Kerr and Beardsell 1975; Boucher et al. 1995; Burgess and Dawson 2004; Breshears et al. 2008; Ewing et al. 2009). Additionally, these occult forms of precipitation and the resultant film of water they deposit on foliage slow or prevent transpiration (Benzing et al. 1978; Barradas and Glez-Medellin 1999). Crown-wetting events brought about by occult precipitation interception may not greatly increase soil water availability and may provide only relatively small quantities of water to the overall ecosystem or plant water budgets (Monteith 1963). However, depending upon their timing, these inputs can provide a crucial water subsidy as an alternative water source to the aboveground parts of plants (Slatyer 1960; Rundel 1982; Oliveira et al. 2005) during periods of water deficit if directly absorbed and used by foliage at the site(s) of interception where demand for water is greatest. 
Generally known as foliar uptake, this type of water absorption occurs when atmospheric water droplets coalesce on plant shoots and move along a water potential gradient (Rundel 1982), from the outside of leaves and stems into internal tissues. Such absorption of water immediately increases foliar hydration (i.e., water content) and plant water potential (Grammatikopoulos and Manetas 1994; Boucher et al. 1995; Yates and Hutley 1995; Gouvra and Grammatikopoulos 2003; Breshears et al. 2008). Other physiological benefits of foliar uptake include enhanced gas exchange after leaves dry (Grammatikopoulos and Manetas 1994; Martin and von Willert 2000; Simonin et al. 2009), increased survival (Stone et al. 1956; Vaadia and Waisel 1963), and even increased plant growth (Boucher et al. 1995). Given the many positive physiological consequences of foliar uptake, this mechanism may be a beneficial water acquisition strategy for species that require a high level of tissue hydration and live where frequent fog, rain, or dew events occur.

To date, studies of foliar uptake occurrence in seasonally dry ecosystems with leaf-wetting events have typically focused on individual species within single habitats (Stone et al. 1950; Stone et al. 1956; Vaadia and Waisel 1963; Benzing et al. 1978; Katz et al. 1989; Grammatikopoulos and Manetas 1994; Yates and Hutley 1995; Boucher et al. 1995; Martin and von Willert 2000; Burgess and Dawson 2004; Oliveira et al. 2005; Breshears et al. 2008; Simonin et al. 2009, but see Munné-Bosch et al. 1999). Not surprisingly, these past investigations demonstrate that foliar uptake is not unique to any one plant species, phylogenetic lineage, or ecosystem type. However, these investigations were not comparative in the sense that they did not evaluate if foliar uptake was a common water acquisition strategy across diverse, co-occurring species within a single ecosystem. Given its clearly demonstrated physiological and ecological importance, we hypothesized that foliar uptake would be widespread among species that inhabit the coast redwood forest where fog water input is a critical water resource (Dawson 1998; Burgess and Dawson 2004; Ewing et al. 2009).

Both canopy trees and understory plants of the redwood forest receive frequent nocturnal marine fog exposure during the summer rainless season (Byers 1953; Oberlander 1956; Azevedo and Morgan 1974; Ewing et al. 2009). The acquisition of fog water by shallow roots that absorb fog dripped from plant crowns to the soil was considered the primary pathway of water uptake by redwood forest plants until Burgess and Dawson (2004) demonstrated that Sequoia sempervirens (D. Don) Endl. (coast redwood) exhibits direct foliar uptake of fog water. If other redwood forest species also exhibit foliar uptake of fog water, the redwood forest ecosystem as a whole gains a potentially significant water subsidy even during short-duration or low-intensity fog events when water input into the soil via fog drip is low.

The present investigation evaluated what proportion of the dominant plant species native to the coast redwood forest ecosystem of Northern California: (1) exhibit foliar uptake, and (2) become more hydrated in response to leafwetting events from fog. We hypothesized that nocturnal fog exposure may improve plant hydration even in species without the capacity for foliar uptake because leaf wetness suppresses nocturnal conductance (water loss at night) and facilitates increased foliar rehydration with soil-derived stem xylem water. To test our hypotheses, we measured the capacity for foliar uptake and nocturnal stomatal conductance by ten dominant redwood forest species and evaluated the effect of crown wetting from fog on leaf hydration and plant water status.

\section{Materials and methods}

\section{Study species}

The ten plant species investigated in this experiment were grown from seed or spore collected from fog-exposed regions of the central redwood forest range. Plants were grown outdoors under shade cloth prior to their transfer into our glasshouse (on the University of California, Berkeley campus). All understory species including Polystichum munitum (Kaulf.) C. Presl (western sword fern), Polypodium californicum Kaulf. (California polypody), Oxalis oregana Nutt. (redwood sorrel), Vaccinium ovatum Pursh (California huckleberry), and Gaultheria shallon Pursh (salal) were approximately 1 year old when the study began. The tree species including Umbellularia californica (Hook. \& Arn.) Nutt. (California bay), Notholithocarpus densiflorus (Hook. \& Arn.) Manos, Cannon \& S. Oh (tanoak; formally known as Lithocarpus densiflorus), Arbutus menziesii Pursh (madrone), Sequoia sempervirens, and Pseudotsuga menziesii (Mirbel) Franco (Douglas-fir) were approximately 2 to 4 years old. The plants were transplanted into potting soil (Supersoil Potting Soil; Supersoil and Rod McLellan, Marysville, Ohio) and allowed to acclimate to glasshouse conditions of a 13-h summertime photoperiod (approximately $700 \mu$ mol PAR midday), day-night temperatures of 15$23^{\circ} \mathrm{C}$, and $60-80 \%$ relative humidity for a minimum of 1 month before the studies began. In the glasshouse during this acclimation period, we shaded $P$. munitum, $P$. californicum, and $O$. oregana with a $2-m m-m e s h$ shade structure $1 \mathrm{~m}$ above their foliage to prevent photoinhibition for these shade-tolerant understory species. To standardize soil water availability across the species, all plants received approximately $700 \mathrm{ml}$ of deionized water every 
3 days including the day before each experiment commenced.

\section{Foliar uptake capacity experiment}

We assessed the capacity for foliar water uptake of each species by measuring direct water absorption into excised leaves and shoots. After $2 \mathrm{~h}$ of post-sunset darkness that simulated typical conditions for nocturnal fog exposure, we cut one mature leaf ( $P$. munitum, $P$. californicum, $O$. oregana, G. shallon, U. californica, $N$. densiflorus, and A. menziesii) or terminal shoot with a photosynthetic stem and mature leaves ( $S$. sempervirens, $P$. menziesii, and $V$. ovatum) from seven plants of each species. We sampled the youngest, fully mature leaves of each species to standardize the foliage by age in order to control for natural cuticle degradation from environmental exposure over time (Mechaber et al. 1996). The surface of each cut petiole or stem segment was immediately sealed with thermosetting adhesive (Adhesive Technologies, Hampton, N.H.) to prevent evaporation from the exposed cut petiole or stem surface during the measurements.

We measured the starting mass of the whole leaf or shoot and then submerged the foliage in deionized water. Complete leaf submergence was used to standardize water availability across the morphologically diverse foliar types of the ten plant species. The foliage was secured in place by clipping the sealed end of each petiole or stem above the waterline. Leaves were submerged in darkness for $180 \mathrm{~min}$ to allow leaf water content to increase in foliage able to absorb water through foliar uptake. We then removed the foliage from the water, patted it thoroughly dry with paper towels, and again recorded the mass to determine how much water the foliage absorbed. To measure whether residual water on the leaf surface persists after towel drying, we first allowed the foliage to air dry briefly so that any remaining surface water would evaporate. Then to account for any potential measurement error associated with this towel-drying method, we weighed this surfacedry foliage, submerged it again in water for $1 \mathrm{~s}$, toweldried the foliage again and immediately re-weighed it. This brief rewetting did not allow sufficient time for water absorption and any increase in mass associated with this second wetting and drying quantified residual water on the leaf surface.

We calculated the amount of foliar uptake for each leaf by evaluating the change in leaf mass after submergence and correcting for residual leaf water as (Eq. 1):

Uptake $=\left(\right.$ Mass $_{2}-$ Mass $\left._{1}\right)-\left(\right.$ Mass $_{4}-$ Mass $\left._{3}\right)$

where, Mass ${ }_{1}$ is the mass before any wetting, Mass 2 is the mass after $180 \mathrm{~min}$ of submergence, $\mathrm{Mass}_{3}$ is the mass after brief air-drying and before rewetting, and Mass 4 is the mass after the brief re-submergence including residual water on the leaf surface. We determined the projected leaf or shoot area of the submerged leaves digitally using the software program ImageJ (US National Institutes of Health, Bethesda, Md.) and standardized the uptake quantity per leaf area $\left(\mathrm{cm}^{2}\right)$. We used a one-sample $t$-test $(\alpha=0.05)$ to determine whether the foliage from each species absorbed significantly more than $0 \mathrm{mg}$ water $\mathrm{cm}^{-2}$ during the submergence and thus exhibited leaf surface permeability to water and a capacity for foliar uptake (SYSTAT 11; SYSTAT Software 2002, San Jose, Calif.).

To determine how foliar uptake influences leaf water content, we calculated the increase in leaf water content (\% LWC) for each submerged leaf as (Eq. 2):

$$
\begin{aligned}
\% \mathrm{LWC}= & {\left[\frac{\left(\mathrm{Mass}_{2}-\left(\mathrm{Mass}_{4}-\mathrm{Mass}_{3}\right)-\mathrm{Mass}_{\text {Dry }}\right)}{\left(\mathrm{Mass}_{1}-\mathrm{Mass}_{\text {Dry }}\right)}-1\right] } \\
& \cdot 100 \%
\end{aligned}
$$

where, Mass ${ }_{\text {Dry }}$ is the dry mass of the leaf measured after drying at $60^{\circ} \mathrm{C}$ for $72 \mathrm{~h}$ and the other variables are as described above (Eq. 1). We used a one-sample $t$-test $(\alpha=0.05)$ to determine if the increase in leaf water content was significantly more than $0 \%$ after submergence.

\section{Plant crown fog-exposure experiment}

To measure how nocturnal leaf wetness from fog affects foliar hydration and plant water status, we compared the effects of crown fog exposure and fogless ambient conditions on plant water potential and leaf water hydrogen isotope composition $\left(\delta^{2} \mathrm{H}\right)$ in the glasshouse. Both the with-fog and without-fog treatments were imposed on potted plants for $6 \mathrm{~h}$ (between 2400 and 0600 hours) inside $1.3 \times 1.5 \times 0.7-\mathrm{m}$ framed chambers covered in clear, polyvinyl sheeting. Each chamber contained an electric, waterproof fan (Adda AQ series; Brea, Calif.) mounted on the wall of the chamber to circulate air and fog. On the opposite chamber wall a data logger (HOBO H8 Pro Series; Onset Computer, Bourne, Mass.) recorded the relative humidity inside the chamber to verify the with-fog treatment maintained complete water vapor saturation of the air during the experiment. Four of the chambers were randomly assigned to the with-fog treatment and were fitted with a 5-1 water reservoir containing a five-disk ultrasonic fog-generating device (Chaoneng Electronics, Nanhai, Guangdong, China) below the chamber fan. Water held in a 20-1 bucket outside of the chamber flowed by gravity into the reservoir through a passive control valve (Hudson Valve, Bakersfield, Calif.) that maintained the water level 
at a depth of approximately $7 \mathrm{~cm}$ for optimal fog generation over the treatment period. For the fogging, we used water that was intentionally enriched by a high evaporation treatment in an open container and elevated approximately $75 \%$ o $\left(\delta^{2} \mathrm{H}\right)$ above the water used to irrigate the plants [fog water $\delta^{2} \mathrm{H}=-3 \%$ Vienna standard mean ocean water $(\mathrm{V}-\mathrm{SMOW})]$. The ultrasonic fog-generating device used did not cause significant fractionation of the fog water (as shown in Burgess and Dawson 2004).

We randomly assigned one plant of each species to a position inside each of the eight treatment chambers. To ensure we exposed only the crown of each plant to the treatment, we isolated the crown from the soil rooting zone by covering the entire pot and soil surface with a 50-1 plastic bag securely attached to the plant base. We tightly sealed the plastic bag around each stem or rachis at the soil level using waterproof adhesive tape and laboratory film (Parafilm; Pechiney Plastic Packaging, Menasha, Wis.) to prevent any transfer of water from the atmosphere into the rooting zone from fog drip or stemflow. This crown isolation occurred for all study plants in the 12-h prior to foliage sampling and treatment application.

Foliage sampling and plant measurements were conducted within a 3-h interval (between 2100 and 2400 hours) just before the start of the overnight treatments. We measured leaf water potential $(\Psi)$ using a Scholander pressure chamber outfitted with a pressure gauge with very fine-scale divisions (every 0.05 MPa; PMS Instruments, Corvallis, Ore.) once per plant to assess plant water status. Concurrently, we collected approximately $0.3 \mathrm{~g}$ of mature leaf tissue per plant crown for leaf water stable hydrogen isotope composition. We immediately sealed the excised leaf samples within 5-ml plastic vials to minimize evaporative enrichment of the cut leaves and stored the samples at $-20^{\circ} \mathrm{C}$ until leaf water extraction and stable hydrogen isotope analysis. After finishing the measurements, the treatment chambers were tightly sealed and the chamber fans circulated ambient air in the without-fog treatment chambers and fog in with-fog treatment chamber for $6 \mathrm{~h}$.

After the nighttime treatment exposure, the chambers were opened and the crowns of all plants were immediately and thoroughly rinsed with deionized water $\left(\delta^{2} \mathrm{H}=-75 \%\right.$ V-SMOW $)$ to remove fog water from the leaf surfaces of the fogged plants and to control for this leaf wetting for non-fogged plants. To remove residual leaf surface water from foliage for sampling, we thoroughly dried individual leaves with paper towels as above and sampled dry foliage for leaf water potential and leaf water hydrogen isotope composition. Additionally, to verify that no water leaked into the soil during the experiment, we collected approximately $3 \mathrm{~g}$ of surface soil directly below the crown of each plant for comparison of the hydrogen isotope composition of the water present in the surface soil between fogged and non-fogged plants.

To assess the effect of the fog treatment on plant water status, we determined the change in leaf water potential overnight for each plant as (Eq. 3):

$\Psi_{\text {difference }}=\Psi_{\text {morning }}-\Psi_{\text {night }}$

and compared the magnitude of this change in water potential between fogged and non-fogged plants across the ten redwood forest species using two-way, fixed factor ANOVA.

To prepare the leaf and soil samples for hydrogen isotope analysis, we extracted the water from each sample without fractionation using cryogenic vacuum distillation (Ehleringer et al. 2000) and the sample extraction times recommended by West et al. (2006). With each daily use of the extraction line, we extracted one known standard water sample to estimate the accuracy and precision of the extraction technique. On average this extracted standard varied from the actual hydrogen isotope value by $-1.06 \pm 0.97 \%$ (mean $\pm \mathrm{SD}$ ). We stored the extracted water samples at $-20^{\circ} \mathrm{C}$ until analysis and determined the hydrogen isotope composition of the leaf water and surface soil water with a dual-inlet CR-reactor interfaced with an isotope ratio mass spectrometer (model Delta plus XL; Finnigan MAT, Breman, Germany). The ratio, ${ }^{2} \mathrm{H} / \mathrm{H}$, is expressed in delta notation (\%) relative to the international standard V-SMOW (Dawson et al. 2002). Data were drift and linearity corrected post-analysis with a quadratic polynomial fitting function based on two quality control standards of very different isotope values placed throughout each mass spectrometry analysis (P. Brooks, unpublished procedure). The long-term external precision of this analysis is $\pm 0.17 \%$.

To determine if leaf wetness from fog initiated the direct foliar uptake of fog water and enhanced leaf overnight rehydration from stem water, we calculated the change in hydrogen isotope ratio $\left(\delta^{2} \mathrm{H}\right)$ of leaf water between the night measurement (before treatment) and the morning measurement (after treatment) for each plant as (Eq. 4):

$\delta^{2} \mathrm{H}_{\text {difference }}=\delta^{2} \mathrm{H}_{\text {morning }}-\delta^{2} \mathrm{H}_{\text {night }}$

We compared the magnitude of this isotopic change overnight between fogged and non-fogged plants across all species using two-way, fixed factor ANOVA.

Back-diffusion of atmospheric water vapor carrying a similar isotope value as the fog water in the with-fog treatment has the potential to affect the isotope composition of leaf water through vapor exchange between the leaf and atmospheric water (Roden and Ehleringer 1999; Farquhar and Cernusak 2005; Lai et al. 2008). However, 
during our experiment the leaf surfaces of all fogged plants became wet very rapidly following the exposure to turbulent airflow with fog and were covered with a thin film of water within 10 min (unpublished data). For this reason the effect of any back-diffusion of vapor from the atmosphere to the bulk leaf water is recognized as a very minor source of error in our measurements for the short time interval before the leaf surfaces were fully covered with a water film.

Nocturnal stomatal conductance

We measured average rates of nocturnal conductance $\left(g_{\mathrm{n}}\right)$ on five plants of each species to determine if these plants lose water at night and therefore undergo further leaf water enrichment when leaf surfaces are dry at night. The measurements were made after $3 \mathrm{~h}$ of post-sunset darkness in the glasshouse and we used only minimal green light (Donovan et al. 1999) from headlamps while conducting the measurements to keep the light conditions at $0 \mu \mathrm{mol} \mathrm{m}{ }^{-2} \mathrm{~s}^{-1}$ photosynthetically active radiation (Quantum Sensor Q39648; LI-COR Biosciences, Lincoln, Neb.). We measured the abaxial stomatal conductance of five mature leaves per individual plant crown using a leaf porometer (model SC-1; Decagon Devices, Pullman, Wash.) in automatic measurement mode calibrated to measure conductance rates in the range of $5-1,000 \mathrm{mmol} \mathrm{H}_{2} \mathrm{O} \mathrm{m}^{-2} \mathrm{~s}^{-1}$. For the coniferous species, $S$. sempervirens and $P$. menziesii, we measured multiple needles in parallel to fully cover the porometer aperture during each measurement. We calculated mean individual plant conductance values first and then species mean conductance values second. We then used a one-sample $t$-test $(\alpha=0.05$ ) to test if each species had mean nocturnal conductance rates significantly above the $5 \mathrm{mmol} \mathrm{H}_{2} \mathrm{O} \mathrm{m}^{-2} \mathrm{~s}^{-1}$ detection limit of the instrument.

\section{Results}

Foliar uptake capacity experiment

Eight of the ten redwood forest species demonstrated the capacity for foliar uptake during the 180-min submergence. Six of the species ( $P$. munitum, P. menziesii, A. menziesii, S. sempervirens, V. ovatum, and $P$. californicum $)$ demonstrated significant $(P<0.05)$ water absorption on a leaf area basis (Fig. 1a). These six species plus $G$. shallon and $N$. densiflorus all showed significant increases $(P<0.05)$ in leaf water content as well (Fig. 1b). The latter species demonstrated only marginally significant absorption when standardized by leaf area despite many replicate leaves showing some uptake. The remaining two species, $U$. californica and $O$. oregana,

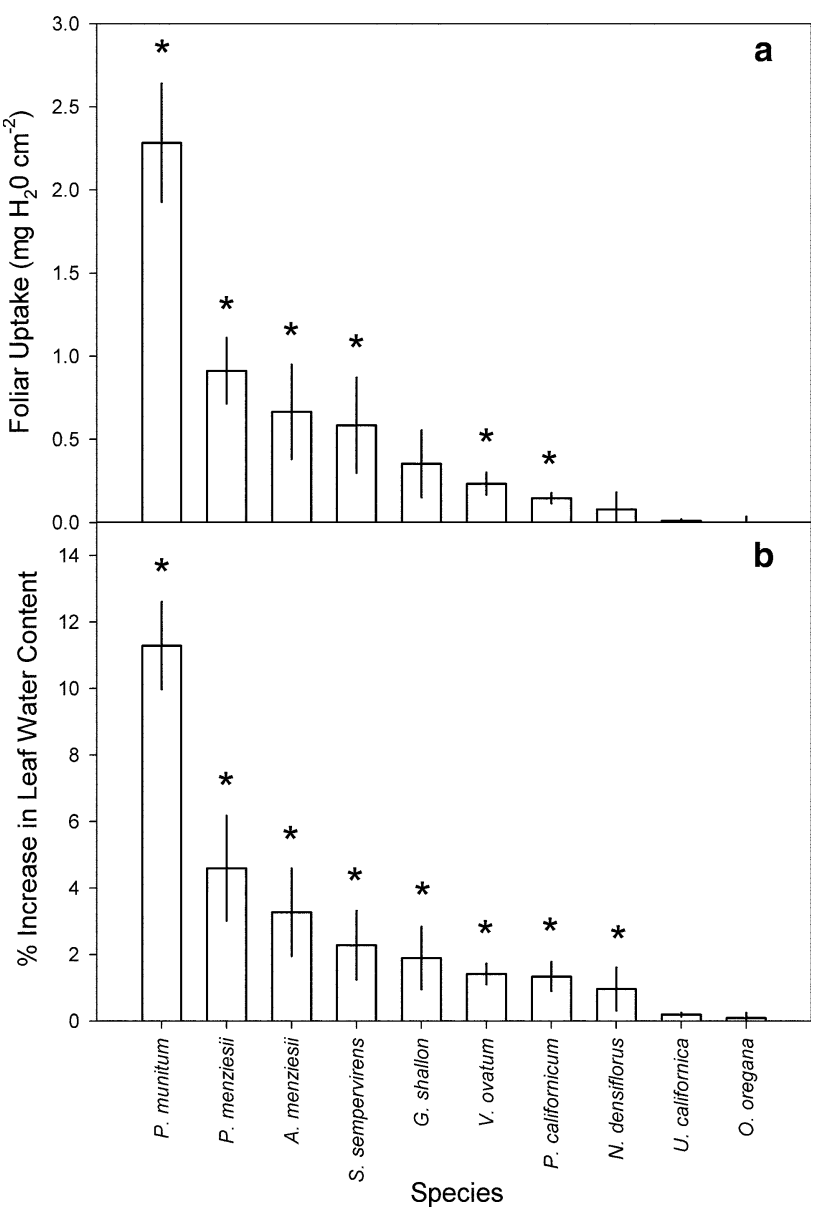

Fig. 1a, b Water absorption by excised leaves or photosynthetic shoots of each species during submergence in deionized water for $180 \mathrm{~min}(n=7)$. a The mean $( \pm \mathrm{SE})$ foliar uptake quantity standardized by projected leaf area. b The mean $( \pm$ SE) \% increase in leaf water content. The asterisk indicates the foliage of each species a absorbed significantly more than $0 \mathrm{mg} \mathrm{H}_{2} \mathrm{O} \mathrm{cm}$ or b significantly increased in leaf water content as determined by a onesample $t$-test $(\alpha=0.05)$

showed neither significant foliar uptake capacity nor increased leaf water content.

Plant crown fog-exposure experiment

As expected, leaf water potential of all species in both the with-fog and without-fog treatments increased during the night as the plants equilibrated with soil water (Fig. 2a). However, fog exposure significantly increased the magnitude of this change $(P=0.003)$ resulting in plants becoming more fully hydrated after the fog exposure (Table 1) when compared to without-fog plants. The interaction between the fog treatment and species was not significant and therefore plants hydrated similarly in response to the fog exposure. The with-fog treatment confined the fog exposure to the crowns of all plants (drip 


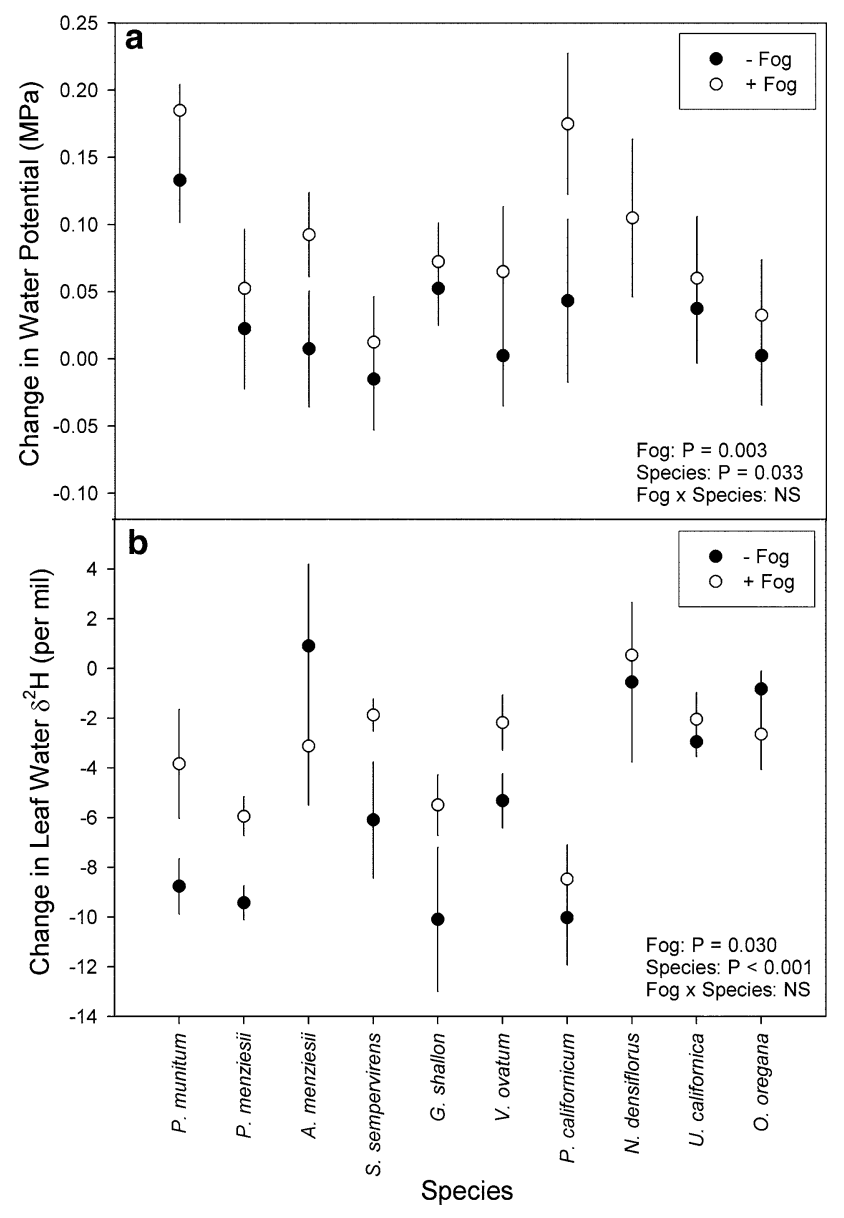

Fig. 2 a The mean $( \pm$ SE) change in leaf water potential for all species in the with-fog $(+F o g)$ and without-fog $(-F o g)$ treatments. The + Fog treatment significantly increased leaf water potential more than the - Fog treatment across species as determined by ANOVA. b The mean $( \pm \mathrm{SE})$ change in leaf water hydrogen isotope ratio $\left(\delta^{2} H\right)$ overnight for all species in the + Fog and - Fog treatments. The + Fog treatment significantly affected the change in the leaf water $\delta^{2} \mathrm{H}$ of fogged plants as determined by ANOVA

from plant crowns to the soil was prevented). This was confirmed with stable isotope analysis of the surface soil water samples taken after treatment exposure that showed no significant difference between the treatments $(P=0.175 ;$ Table 1$)$. These data clearly show that no fog water leaked into the soil during the fog treatment and that all plant responses to the fog treatment came only from crown wetting.

The leaf water $\delta^{2} \mathrm{H}$ generally decreased overnight across all of the study species in both fog treatments (Fig. 2b). This change reflects the addition of ${ }^{2} \mathrm{H}$-depleted stem water (derived from the soil) to the leaf water pool (that is generally enriched from the previous day's water loss via transpiration). However, the leaf water $\delta^{2} \mathrm{H}$ of plants in the with-fog treatment decreased significantly less across most species (higher morning leaf water $\delta^{2} \mathrm{H}$ in the with-fog treatment) when compared with plants in the without-fog treatment $(P=0.030$; Table 1). This general trend demonstrates that fog water with a high $\delta^{2} \mathrm{H}$ was directly absorbed into internal leaf tissues and confirms that foliar uptake occurred. The smaller decrease in $\delta^{2} \mathrm{H}$ in the with-fog treatment (relative to the without-fog treatment) cannot be due to leaf water evaporative enrichment in the fog-exposed plants because of the complete suppression of any nocturnal conductance by the water vapor saturation of the atmosphere (relative humidity reached 100\%). Due to the lower humidity in the without-fog treatment $(93.6 \pm 4.7 \%$, mean $\pm \mathrm{SD}$ ), we know that nocturnal conductance was not fully suppressed (see below) and thus, conductance in some species minimized the overnight decrease in leaf water $\delta^{2} \mathrm{H}$ of plants from the without-fog treatment. While the mean decrease in leaf water $\delta^{2} \mathrm{H}$ was slightly greater in the with-fog treatment for both A. menziesii and $O$. oregana, there was no significant statistical interaction between the fog treatment and species factors in the model (Table 1).

Nocturnal stomatal conductance

Six of the ten species ( $P$. munitum, P. menziesii, A. menziesii, V. ovatum, $P$. californicum, and $N$. densiflorus) exhibited significant $(P<0.05)$ nocturnal conductance above the instrument detection limit $\left(g_{\mathrm{n}}\right.$; Table 2$)$. The remaining four species ( $S$. sempervirens, G. shallon, $U$. californica, and $O$. oregana) demonstrated no significant nocturnal conductance above the detection limit.

Table 1 ANOVA table for the effects of species and the fog treatment on the overnight change in plant water potential, leaf water hydrogen isotope ratio $\left(\delta^{2} H\right)$, and post-treatment surface soil water $\delta^{2} \mathrm{H}$

\begin{tabular}{|c|c|c|c|c|c|c|c|c|c|c|c|c|c|c|c|}
\hline \multirow[t]{2}{*}{ Effect } & \multicolumn{5}{|c|}{ Change in water potential } & \multicolumn{5}{|c|}{ Change in leaf water $\delta^{2} \mathrm{H}$} & \multicolumn{5}{|c|}{ Soil water $\delta^{2} \mathrm{H}$} \\
\hline & $d f$ & SS & MS & $F$ & $P$ & $d f$ & SS & MS & $F$ & $P$ & $d f$ & SS & MS & $F$ & $P$ \\
\hline Species $(S)$ & 9 & 13.3 & 1.48 & 2.23 & 0.033 & 9 & 722 & 80.3 & 6.18 & $<0.001$ & 9 & 1,950 & 216 & 7.76 & $<0.001$ \\
\hline Fog $(F)$ & 1 & 6.49 & 6.49 & 9.78 & 0.003 & 1 & 64.1 & 64.1 & 4.94 & 0.030 & 1 & 52.6 & 52.6 & 1.89 & 0.175 \\
\hline$S \times F$ & 9 & 3.95 & 0.44 & 0.66 & 0.739 & 9 & 150 & 16.7 & 1.29 & 0.264 & 9 & 125 & 13.6 & 0.50 & 0.869 \\
\hline Error & 59 & 39.1 & 0.66 & & & 59 & 767 & 13.0 & & & 58 & 1,620 & 27.9 & & \\
\hline
\end{tabular}


Table 2 The mean rate $\left( \pm\right.$ SE) of nocturnal conductance $\left(g_{n}\right)$ for each species $(n=5)$

\begin{tabular}{lrll}
\hline Species & \multicolumn{1}{l}{$g_{\mathrm{n}}$} & Species & $g_{\mathrm{n}}$ \\
\hline P. munitum & $23 \pm 5^{*}$ & V. ovatum & $17 \pm 5^{*}$ \\
P. menziesii & $34 \pm 2^{*}$ & P. californicum & $36 \pm 5^{*}$ \\
A. menziesii & $32 \pm 5^{*}$ & N. densiflorus & $50 \pm 8^{*}$ \\
S. sempervirens & $6 \pm 1$ & U. californica & $<5$ \\
G. shallon & $12 \pm 4$ & O. oregana & $<5$ \\
\hline
\end{tabular}

$* \alpha=0.05$, significant conductance rate above the instrument detection limit of $5 \mathrm{mmol} \mathrm{H}_{2} \mathrm{O} \mathrm{m}^{-2} \mathrm{~s}^{-1}$ as determine by a onesample $t$-test

\section{Discussion}

Foliar uptake in redwood forest species

Leaf wetting and subsequent water uptake increases foliar hydration in the majority of redwood forest species we investigated. We determined through the immersion of foliage in water that $80 \%$ of dominant redwood forest species studied exhibit leaf surface permeability to water and therefore share the capacity to absorb water directly into photosynthetic tissues (leaves and stems). This confirms that this water acquisition strategy is widespread across species in this ecosystem and is not unique to any one taxonomic group or phylogenetic lineage. The species we studied range widely in leaf morphology and growth habit (Fig. 3) from coniferous and broadleaf canopy trees (P. menziesii, A. menziesii, S. sempervirens, and $N$. densiflorus) to understory ferns ( $P$. munitum and $P$. californicum) and broadleaf shrubs (G. shallon and $V$. ovatum). Interestingly, all of the species that show foliar uptake capacity reside in habitats throughout their native ranges that may or may not receive fog and therefore it seems that foliar uptake capacity is not restricted to endemic species of strictly fog-inundated redwood ecosystems.

Foliar uptake increased mean leaf water content in half of the species investigated by $2-11 \%$ (Fig. 1b). This increased hydration occurred despite the fact the plants were adequately hydrated during the investigation and the water potential driving gradient across the leaf surface was therefore small (Slatyer 1960; Rundel 1982). Enhanced leaf water stress increases the driving gradient for absorption and allows foliar tissues to store more water. Therefore, foliar uptake capacity may increase with moderate plant drought stress until the pathway for absorption at the leaf surface is restricted by dehydration from increased levels of drought stress. While the specific pathway of water entry into the leaves of our species remains unknown, research into water uptake pathways in other plant taxa shows that water can diffuse into leaves through the cuticle (Slatyer 1960; Vaadia and Waisel 1963; Suarez and Gloser 1982; Yates and Hutley 1995; Gouvra and Grammatikopoulos 2003), particularly in species without specialized uptake channels like hydathodes (Martin and von Willert 2000) or absorbent trichomes (Franke 1967; Benzing et al. 1978). Assuming that the cuticle is a viable pathway for water entry in our study species (none of these plants are known to possess hydathodes or absorbent trichomes) extreme water stress could limit foliar uptake due to the contraction of the epidermis and cuticle from dehydration. This is supported by the previous work of Burgess and Dawson (2004) who saw a marked decline in foliar uptake by highly water-stressed mature foliage of $S$. sempervirens. Given that foliar uptake increases foliar hydration however, frequent leaf-wetting events may actually promote foliar uptake occurrence by increasing cuticle and epidermal hydration, therefore extending the length of time surface water uptake may occur during periods of increasing soil water deficit.

Leaf wetness may increase plant hydration in two ways, either by providing a direct water subsidy accessible through foliar uptake that increases tissue water content or by suppressing leaf water loss to the atmosphere and thereby facilitating more efficient foliar hydration with stem xylem water from the rooting zone (see Fig. 3 for the relative magnitude of both hydrating mechanisms among species). Our fog experiment provides stable isotope evidence for both mechanisms contributing to improved plant hydration in redwood forest plants. As shown in other foliar uptake studies, the isotopic composition of leaf water changes in response to the foliar absorption of exogenous water (Burgess and Dawson 2004; Breshears et al. 2008). If the plants exposed to leaf wetting from fog in this study only received water into their leaves from soil-derived stem water during the experiment, the leaf water $\delta^{2} \mathrm{H}$ would have decreased in the same magnitude as the control plants. Instead, the leaf water $\delta^{2} \mathrm{H}$ of plants with wet crowns generally decreased less, indicating the absorption of fog water with a high $\delta^{2} \mathrm{H}$. The directional change in leaf water $\delta^{2} \mathrm{H}$ was still negative for these fog-exposed plants despite the absorption of ${ }^{2} \mathrm{H}$-enriched fog water from the leaf surface because of the large contribution from ${ }^{2} \mathrm{H}$-depleted stem xylem water entering the leaves during nocturnal equilibration with soil water.

Interestingly, A. menziesii deviated most from the general trend in leaf water $\delta^{2} \mathrm{H}$ when plants with wet and dry leaves were compared. The increased mean leaf water $\delta^{2} \mathrm{H}$ observed in leaves without leaf wetting provides evidence that evaporative enrichment occurred in the without-fog treatment, suggesting that nocturnal conductance may have affected the leaf water $\delta^{2} \mathrm{H}$ of the plants with dry leaves. 
Fig. 3 Leaf wetting increases foliar hydration in many of the dominant broadleaf, coniferous, and fern species of the redwood forest ecosystem. Each box illustrates the leaf morphology of one species with grey arrows illustrating the magnitude of foliar uptake capacity $(U$; arrow thickness represents the foliar uptake capacity of each species relative to the maximum capacity measured) and black arrows illustrating water conservation when leaf wetting stops nocturnal water loss through stomata $\left(g_{\mathrm{n}}\right.$; arrow thickness represents the nocturnal conductance rate of each species relative to the maximum rate measured). These species are ranked in order of how influential foliar uptake may be for leaf hydration relative to the suppression of nocturnal conductance when leaves are wet. $P$. munitum is ranked first because it demonstrated the highest ratio of foliar uptake capacity to nocturnal conductance and $U$. californica and $O$. oregana are ranked last because no foliar uptake capacity was measured. All illustrated species either experience leaf wetting in the canopy of redwood forest where fog impaction and interception occurs first during fog exposure or on the forest floor where occult precipitation delivers fog water after the canopy foliage saturates. Crown silhouettes on the left indicate the relative position of each species within the redwood forest profile

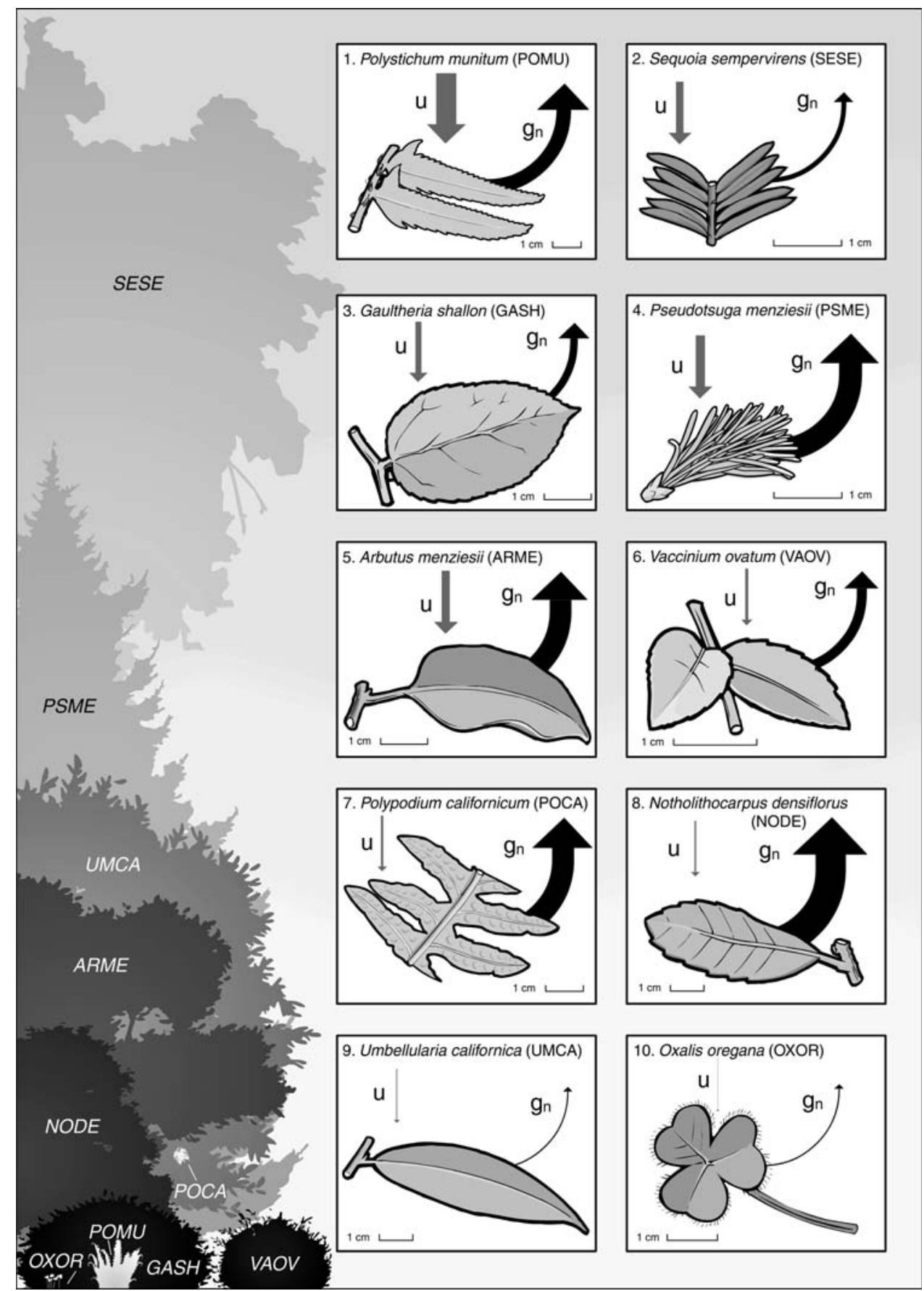

Since we found that leaves of $A$. menziesii have the capacity for foliar uptake when submerged and also exhibit nocturnal conductance when dry, these data demonstrate that the deuterium stable isotope technique we applied here may not always be able to determine if a species conducts foliar uptake. Given that nocturnal conductance occurs in numerous species across many types of ecosystems (Donovan et al. 1999; Snyder et al. 2003; Caird et al. 2007; Dawson et al. 2007) and in $60 \%$ of the redwood forest species we investigated, other redwood forest species that did not receive fog exposure may have also exhibited nocturnal conductance during the experiment, thereby minimizing the measured difference in leaf water $\delta^{2} \mathrm{H}$ between the treatments. While the frequency of nocturnal conductance among redwood forest species complicates the use of stable isotopes to study foliar uptake, it demonstrates that leaf wetness may be important in stopping nocturnal conductance to water vapor, thereby promoting 
plant water conservation even in plants without the capacity for foliar uptake.

\section{The role of leaf-wetting events}

Leaf wetting occurs with high frequency throughout the year in the coast redwood forest ecosystem. While rain causes most leaf wetness during the winter and spring months (October-May) this water subsidy also significantly increases soil moisture (Dawson 1998; Ewing et al. 2009). Therefore, the leaf wetting effects of rain on plant water status is likely dominated by root uptake during the rainy season. In contrast, leaf wetting is strongly influential during the summer rainless season when fog is the only water subsidy because fog is commonly intercepted only by the crowns of fog-exposed plants. Fog travels horizontally into redwood forests until it is intercepted by the forest canopy (Byers 1953; Oberlander 1956; Azevedo and Morgan 1974; Dawson 1998; Ewing et al. 2009). Once the leaf surfaces of the overstory tree crowns become saturated, excess water drips down through the forest, wetting the crowns of the understory plants below (see Fig. 3 for an illustration of the vertical profile of the forest community and the spatial arrangement of redwood forest species).

Most of the dominant species investigated from the redwood ecosystem show increased foliar hydration after this type of leaf-wetting event, suggesting that these species have leaves with a high sensitivity to leaf wetness that both absorb and conserve water when wet (see Fig. 3; species 1-8). While both foliar uptake capacity and the suppression of nocturnal stomatal conductance likely contribute to leaf hydration in the high-sensitivity species when leaves are wet, the ratio of foliar uptake capacity to nocturnal water loss reveals the relative influence of foliar uptake on the hydration process. In Fig. 3, species are ranked by the potential contribution of foliar uptake to total foliar hydration. This shows that foliar uptake may contribute proportionally less to foliar hydration in species that can hydrate primarily from suppressed nocturnal stomatal conductance (high $g_{\mathrm{n}}$; species 7-8) or possess minimal foliar uptake capacity (low $U$; species 9-10). Only two species have leaves with extremely low sensitivity to leafwetting events overall and their foliage appears nocturnally impervious to both water uptake and water loss when wet (Fig. 3; species 9-10). For these few species that appear minimally responsive to leaf wetness, uptake of fog water dripped from overstory trees to the soil likely constitutes the primary pathway for fog water acquisition and summertime drought alleviation.

When fog water becomes available in the rooting zone during significant fog inundation, root uptake likely contributes to fog water acquisition for all redwood forest species since plant roots are specialized for water absorption. However, determining the relative contributions of foliar versus root uptake pathways to total plant fog water acquisition proves difficult in the field. Dawson (1998) showed that all five dominant redwood forest species he investigated ( $S$. sempervirens, P. munitum, O. oregana, G. shallon, and Rhododendron macrophyllum) contained significant quantities of fog water in their tissues during the summer months. While the mechanism by which these species acquired the fog water was not known, Dawson (1998) assumed it was via root water uptake. From our current findings, we now recognize that three out of four of these species (we did not evaluate the uptake capacity of R. macrophyllum) exhibit foliar uptake (S. sempervirens, $P$. munitum, and G. shallon). Further, we strongly suspect that under some circumstances the high foliar uptake capacity we found in $P$. munitum allows this dominant understory fern to rely completely on fog water during the summer when fog exposure is frequent (as shown in Dawson 1998). By readily capturing fog water with its leaves, $P$. munitum and the other foliar water-absorbing species are likely to obtain these important fog water subsidies even during brief fog events that contribute little or no water to the soil. Interestingly, fog frequency has declined over the past $50+$ years along the entire coast of the western United States (Johnstone 2008). This climate change of course means that the frequency of summertime leaf-wetting events has simultaneously declined. The implications of such changes are not yet known, but given the demonstrated importance of fog water for redwood forest plants it seems likely that the levels of plant water stress will increase as this important water subsidy is lost.

The improved water status of the redwood forest vegetation as a whole resulting from foliar uptake of fog water has important community and ecosystem-scale consequences, particularly during the otherwise rain-free summer. When plants absorb water directly from leaf surfaces, their water status can increase above the hydration state supported by soil water alone. This subsidizes the ecosystem water balance (Dawson 1998) and largely decouples plant crowns from soil water sources, therefore modifying our perspective on the unidirectional nature of the soil-plant-atmospheric continuum as recently discussed by Simonin et al. 2009. This phenomenon is not unique to redwood forests or species since the literature clearly indicates many species that inhabit a wide range of ecosystems exhibit improved plant water status (higher water potentials) following exposure to crown-wetting events (Grammatikopoulos and Manetas 1994; Boucher et al. 1995; Yates and Hutley 1995; Gouvra and Grammatikopoulos 2003; Breshears et al. 2008, and others). Redwood forest species generally follow the same trend, highlighting the widespread nature and physiological 
importance of leaf wetting for many vegetation types. Due to their high initial water status, the absolute magnitude of the water potential improvement observed in the redwood forest species in this experiment was smaller (Fig. 2) than that shown in other studies (for examples see Munné-Bosch et al. 1999; Gouvra and Grammatikopoulos 2003; Breshears et al. 2008). However, it constitutes a physiologically significant improvement in water status as shown by Burgess and Dawson (2004) and Simonin et al. 2009 for $S$. sempervirens and observed in P. munitum (unpublished data). Given that many physiological responses to changes in water potential are nonlinear, even small increases in water potential may greatly affect leaf function and plant growth by increasing solute transport, photosynthetic rates, and cellular expansion (Larcher 1995; Kramer and Boyer 1995; Burgess and Dawson 2004; Burgess et al. 2006; Simonin et al. 2009). As noted above, further reductions in fog frequency associated with climate change will in fact reduce the availability of these critical leaf-wetting events that can increase leaf water potential, promote growth, and maybe even survival for many of these redwood forest plants during the summer drought.

In summary, redwood forest plants experience increasing soil drought when rain frequency drops severely during the summer months (Dawson 1998) and yet receive frequent leaf wetting from fog (Byers 1953; Oberlander 1956; Azevedo and Morgan 1974). These leaf-wetting events can increase the hydration state of many dominant redwood forest species, both by suppressing nocturnal conductance and providing a direct water subsidy to leaves. While our investigation only focused on plants of the redwood forest ecosystem, it seems clear that foliar water uptake is far more widespread (citations above) and that by using water deposited on their crowns, plants from many ecosystems with similar demands for water and frequent exposure to leaf-wetting events may also possess the foliar water acquisition strategy. Future research should pursue identifying how many plant species exhibit foliar uptake and respond physiologically to leaf wetting across ecosystems so that we can more accurately include this water uptake route in estimates of ecosystem water balance and also better predict the effect of changing water availability on ecosystem function.

Acknowledgments This project was supported in part by a Wang Graduate Fellowship to E. L. from the Department of Integrative Biology at the University of California, Berkeley and grants from the Save-the-Redwoods League. The authors thank Michal Shuldman and Rebecca Welch for sampling assistance, Paul Brooks at the University of California Berkeley Center for Stable Isotope Biogeochemistry for analytical support, and the Dawson Laboratory and three anonymous reviewers for valuable comments that improved the manuscript. We especially thank one reviewer whose suggestions very much improved the presentation of the data.
Open Access This article is distributed under the terms of the Creative Commons Attribution Noncommercial License which permits any noncommercial use, distribution, and reproduction in any medium, provided the original author(s) and source are credited.

\section{References}

Azevedo J, Morgan DL (1974) Fog precipitation in coastal California forests. Ecology 55:1135-1141

Barradas VL, Glez-Medellin MG (1999) Dew and its effect on two heliophile understorey species of a tropical dry deciduous forest in Mexico. Int J Biometeorol 43:1-7

Benzing DH, Seemann J, Renfrow A (1978) Foliar epidermis in Tillandsioideae (Bromeliaceae) and its role in habitat selection. Am J Bot 65:359-365

Boucher JF, Munson AD, Bernier PY (1995) Foliar absorption of dew influences shoot water potential and root-growth in Pinus strobus seedlings. Tree Physiol 15:819-823

Breshears DD, McDowell NG, Goddard KL, Dayem KE, Martens SN, Meyer CW, Brown KM (2008) Foliar absorption of intercepted rainfall improves woody plant water status most during drought. Ecology 89:41-47

Burgess SSO, Dawson TE (2004) The contribution of fog to the water relations of Sequoia sempervirens (D. Don): foliar uptake and prevention of dehydration. Plant Cell Environ 27:1023-1034

Burgess SSO, Pitterman JA, Dawson TE (2006) Hydraulic efficiency and safety of branch xylem increases with height in Sequoia sempervirens (D. Don) crowns. Plant Cell Environ 29:229-239

Byers HR (1953) Coast redwoods and fog drip. Ecology 34:192-193

Caird MA, Richards JH, Donovan LA (2007) Nighttime stomatal conductance and transpiration in C-3 and C-4 plants. Plant Physiol 143:4-10

Dawson TE (1998) Fog in the California redwood forest: ecosystem inputs and use by plants. Oecologia 117:476-485

Dawson TE, Mambelli S, Plamboeck AH, Templar PH, Tu KP (2002) Stable isotopes in plant ecology. Annu Rev Ecol Syst 33:507559

Dawson TE, Burgess SSO, Tu KP, Oliveira RS, Santiago LS, Fisher JB, Simonin KA, Ambrose AR (2007) Nighttime transpiration in woody plants from contrasting ecosystems. Tree Physiol 27:561575

Donovan LA, Grise DJ, West JB, Pappert RA, Alder NN, Richards JH (1999) Predawn disequilibrium between plant and soil water potentials in two cold-desert shrubs. Oecologia 120:209-217

Ehleringer JR, Roden J, Dawson TE (2000) Assessing ecosystemlevel water relations through stable isotope ratio analyses. In: Sala O, Jackson R, Mooney HA, Howarth R (eds) Methods in ecosystem science. Springer, New York, pp 181-198

Ewing HA, Weathers KC, Templer PH, Dawson TE, Firestone MK, Elliott AM, Boukili VKS (2009) Fog water and ecosystem function: heterogeneity in a California redwood forest. Ecosystems $12: 417-433$

Farquhar GD, Cernusak LA (2005) On the isotopic composition of leaf water in the non-steady state. Funct Plant Biol 32:293-303

Franke W (1967) Mechanisms of foliar penetration of solutions. Annu Rev Plant Physiol 18:281-300

Gouvra E, Grammatikopoulos G (2003) Beneficial effects of direct foliar water uptake on shoot water potential of five chasmophytes. Can J Bot 81:1280-1286

Grammatikopoulos G, Manetas Y (1994) Direct absorption of water by hairy leaves of Phlomis fruticosa and its contribution to drought avoidance. Can J Bot 72:1805-1811 
Johnstone JA (2008) Climate variability of Northern California and its global connections. Dissertation, Department of Geography, University of California, Berkeley

Katz C, Oren R, Schulze E-D, Milburn JA (1989) Uptake of water and solutes through twigs of Picea-abies (L.) Karst. Trees 3(3):3-37

Kerr JP, Beardsell MF (1975) Effect of dew on leaf water potentials and crop resistances in a Paspalum pasture. Agron J 67:596-599

Kramer PJ, Boyer JS (1995) Water relations of plants and soils. Academic Press, San Diego

Lai C-T, Ometto JPHB, Berry JA, Martinelli LA, Domingues TF, Ehleringer JA (2008) Life form-specific variations in leaf water oxygen-18 enrichment in Amazonian vegetation. Oecologia 157:197-210

Larcher W (1995) Physiological plant ecology, 3rd edn. Springer, Berlin

Martin CE, von Willert DJ (2000) Leaf epidermal hydathodes and the ecophysiological consequences of foliar water uptake in species of Crassula from the Namib Desert in Southern Africa. Plant Biol 2:229-242

Mather JR, Yoshioka GA (1968) The role of climate in the distribution of vegetation. Ann Assoc Am Geogr 58:22-41

Mechaber WL, Marshall DB, Mechaber RA, Jobe RT, Chew FS (1996) Mapping leaf surface landscapes. Proc Natl Acad Sci USA 93:4600-4603

Monteith JN (1963) Dew: facts and fallacies. In: Rutter AV, Whitehead FH (eds) The water relations of plants. Blackwell, Oxford, pp 37-56

Munné-Bosch S, Nogués S, Alegre L (1999) Diurnal variations of photosynthesis and dew absorption by leaves in two evergreen shrubs growing in Mediterranean field conditions. New Phytol 144:109-119

Oberlander GT (1956) Summer fog precipitation on the San Francisco Peninsula. Ecology 37:851-852

Oliveira RS, Dawson TE, Burgess SSO (2005) Evidence for direct water absorption by the shoot of the desiccation-tolerant plant
Vellozia flavicans in the savannas of central Brazil. J Trop Ecol 21:585-588

Roden JS, Ehleringer JR (1999) Observations of hydrogen and oxygen isotopes in leaf water confirm Craig-Gordon model under wide-ranging environmental conditions. Plant Physiol 120:1165-1173

Rundel PW (1982) Water uptake by organs other than roots. In: Lange OL, Nobel PS, Osmond CB, Ziegler H (eds) Physiological plant ecology II: water relations and carbon assimilation. Springer, Berlin, pp 111-134

Simonin KA, Santiago LS, TE Dawson (2009) Fog interception by Sequoia sempervirens (D.Don) crowns decouples physiology from soil water deficit. Plant Cell Environ 32:882-892

Slatyer RO (1960) Absorption of water by plants. Bot Rev 26:331392

Snyder KA, Richards JH, Donovan LA (2003) Night-time conductance in C-3 and C-4 species: do plants lose water at night? J Exp Bot 54:861-865

Stephenson NL (1990) Climatic control of vegetation distribution: the role of the water balance. Am Nat 135:649-670

Stone EC, Went FW, Young CL (1950) Water absorption from the atmosphere by plants growing in dry soil. Science 111:546-548

Stone EC, Shachori AY, Stanley RG (1956) Water absorption by needles of Ponderosa pine seedlings and its internal redistribution. Plant Physiol 31:120-126

Suarez AG, Gloser J (1982) Time course of foliar absorption of water in Panicum and Paspalum. Biol Plant 24:226-230

Vaadia Y, Waisel Y (1963) Water absorption by aerial organs of plants. Physiol Plant 16:44-51

West AG, Patrickson SJ, Ehleringer JR (2006) Water extraction times for plant and soil materials used in stable isotope analysis. Rapid Commun Mass Spectrom 20:1317-1321

Yates DJ, Hutley LB (1995) Foliar uptake of water by wet leaves of Sloanea woollsii, an Australian subtropical rain-forest tree. Aust J Bot 43:157-167 